\title{
Bernie Blais, Deputy Minister of Health and Social Services, Nunavut
}

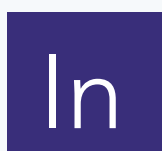

the Fall of 2005, Consulting Editor Ken Tremblay interviewed Bernie Blais, Nunavut's Deputy

Minister of Health and Social Services - a position he had held since July of 2002. In addition to his duties as Deputy Minister, Mr. Blais's portfolio included people with disabilities and the status of women. Since the interview, Mr. Blais has announced he has accepted the position of CEO of Alberta's Northern Lights Health Region.

HQ: Tell us more about your portfolio.

Blais: Our annual budget is $\$ 250$ million with $\$ 25$ million for capital projects. We have 800 staff spread across 25 communities and two million square kilometres. The population of Nunavut is 28,000 and communities range from 300 to 6,000 people. About $85 \%$ of the population are Inuit. There are no roads: generally, movement of patients, personnel and supplies is by air. The only time we can distribute and receive medical and other supplies by barge or ship is in the summer. Our travel budget for medical care is around $\$ 40$ million; about 28 cents of every health dollar goes to take people to and from care.

We have one hospital in Iqaluit and a newly opened facility in Rankin Inlet. We have another small hospital in Cambridge Bay, our furthest point west. We are building new capacity in Nunavut: to deliver more care and more services in the North. That's our strategic plan - to bring healthcare closer to home.

HO: What keeps you awake at night as Deputy Minister of Health and Social Services in Nunavut?

Blais: Well, quite a few things. But the basic theme ... centres around shortages of staff and health professionals. We are very dependent currently on southern providers for many of our nurses, doctors and other health professionals. Recruitment and retention have been the biggest challenge of my role. In the last couple of years, we have really made progress.

HQ: When you say "progress," what are your indicators?

Blais: Last year, we were very desperate for staff. This year, we recruited eight new physicians (with three more coming) to the hospital in Iqaluit. And we have some good prospects for the other regions as well. Because we have a lot of itinerant providers in the territory, permanent relocations are a big step for us. As well, we recruited 52 international graduates in nursing to replenish the shortage of nurses we have in Nunavut. Our first group will arrive this fall from the Philippines and India. On the home front, we graduated our first four nurses from Arctic College, a partnership program with Dalhousie University.
HQ: What experiences in the south have served you well in your role?

Blais: Restructuring. I was involved in major restructuring in Manitoba, Ontario and BC. I bring that wealth of experience to Nunavut. As well, I came up through the ranks via purchasing, housekeeping, risk management [and] construction, and [I] am a paramedic by training. We have a very small leadership team so that experience has been portable. My lifetime of experience has come together perfectly in Nunavut. You need that type of background to do this job.

Southern Canada is very fortunate - perhaps spoiled, with easy access to CT scans and MRIs even if you have to wait a little bit. The south is well resourced for mental health resources, adequate support structures; you don't have to fly people everywhere and provide translation services at every turn. People can drive to their local hospital. 
HQ: What have been your lessons learned as Deputy Minister? Blais: My whole view of health services has changed since I arrived. Primary healthcare in the north is further ahead than jurisdictions in the south. In Nunavut, over $80 \%$ of first contacts with patients are with nurses. The rest of Canada can learn from Nunavut on how to deliver primary healthcare. We are not a very rich province or territory, yet we provide excellent primary care in Canada's most complex and ... harshest environments.

We have translators everywhere because southern providers don't speak Inuktitut. Imagine a jurisdiction where everything you did was through a translator and/or medical interpreter. What complexity would this add to your job every day? We have interpreters throughout the territory. When I visit a community, I need an interpreter to speak to community leaders.

Nunavut is a community-based environment. Familyoriented services are very important to people in isolated communities. We do extensive community consultation with any major change to services. The lessons I am learning now are those I should have used 20 years ago.

HQ: I understand you have implemented some creative solutions to address your human resources challenges. Can you give us some examples?

Blais: We just graduated a class of radiography assistants. These people used to be custodians, medical interpreters and clerks. We also graduated 12 others to do more complex X-rays in many remote communities. The course is a joint venture offered through Mohawk College and McMaster University.

It is astonishing when you see the potential we have in our community, that people can learn new skills once you take the time to organize tailored programs. We're launching others for mental health workers, maternal care workers, dental aides and midwives. Most of that training will occur in Nunavut, through technology, hands-on training and academic partnerships.

All of our programs are designed to allow people to grow at their own pace and encourage them to develop further. Our master plan for education and training was launched in the Fall.

HQ: Any other examples of innovative technology deployment, given the geography and the realities of the north?

Blais: Absolutely. We have invested heavily in telehealth technology; in fact, all of our health centres are linked. Not only do we use it for distance education and specialist consultations, but also for high-risks moms who might be sent out of territory 8 to 10 weeks before they deliver. We have what we call weekly visitations: we connect [the moms'] location to their families at home, so they can visit their families. We're using technology in ways that we never even dreamed of, and that's one of them.

However, we have very little IT infrastructure. We have just completed an e-health blueprint and are mapping a five-year strategy through Canada Health Infoway. Those plans include radiology and pharmacy. We are at least 10 years behind most jurisdictions. The nice thing: we don't have any legacy issues, and there is a high acceptance rate of IT. People want technology; it's not like you're fighting to get it in.

HQ: Bernie, as a territorial member of the National Quality Health Council, what experiences or what priorities are most germane to Nunavut?

Blais: Nunavut has one of the least healthy populations in Canada, and we need to communicate that reality to the Health Council. We hosted the Health Council in September 2004. It was an eye-opener for them to see, first-hand, our resources and infrastructure. We need Council's help, and their visit put us on the radar.

We invited Canada's nursing leadership to Nunavut for a four-day study tour with our key players. It was hard for them to conceive of no roads, where you have to fly everybody everywhere, provide interpreters and, during harsh weather, [where] staff or patients [can get] stuck in distant locations for weeks at a time. Even in the summer, fog can strand people for days. While our geography is huge, so are [our] weather issues.

\section{HQ: What's the political landscape like for you as Deputy Minister?}

Blais: Healthcare has been a priority of [our] government because of the many needs and the lack of infrastructure. [We] have invested heavily: new hospitals and community health centres are opening up, [and] we are investing in education and training ... operating budgets have increased substantially. We are investing about $\$ 110$ million in infrastructure for healthcare and other portfolios.

The major issue is that the decision-making process can be slow, an issue for any government. Yet, the support that this department has received for all of its initiatives is remarkable.

HQ: The public is concerned about "waiting times," and you have said "closer to home" a few times. Is this issue driving the agenda of Nunavut?

Blais: When you look at the volume of clients we send to other jurisdictions, many could have received care ... at home. But we need infrastructure to do that. Two years ago, we had 60,000 boarding home days out of territory and issued 24,000 airline tickets.

By repatriating clients, there is a return on any investment. And the other challenge is to train people here to do those jobs in the future. It is an economic opportunity to develop capacity in Nunavut; improving the health of Canadians includes addressing socio-economic factors. Developing a homegrown workforce gives us the opportunity to reinvest resources in infrastructure and human capacity. 
Insight

HQ: How has your family adjusted to life in the north? Blais: It's been a major adjustment for my wife; she is away from her kids and grandchildren. She is working too and has learned a lot herself [about] Canada and the notion of giving back to communities. You cannot live in a community like this and not give something back. Barbara is heavily involved with the women's shelter of Iqaluit.

Nunavut is a beautiful place. It's pristine, unpolluted and different from the rest of Canada; it has its own beauty and spirituality.

Let me just say this - life in the North is not for the light-hearted. It is for someone who really wants to make a difference in this world and is prepared to make that kind of professional and personal commitment.

HQ: Last call - any pearls of wisdom for the readers of Healthcare Quarterly?

Blais: There are many lessons to be learned from Nunavut and ... challenges. I would encourage anyone to consider a work experience here because it changes your life for the better. This is probably the most rewarding job I've ever done in my career. I believe I am making a difference. I appreciate this opportunity to tell our story.

\section{First CIHI Executive Director for Ontario}

Ms. Glenda Yeates, President and Chief Executive Otficer of the Canadian Institute for Health Information (CIHI), is pleased announce the appointment of Mr. Jack Bingham to the position of Executive Director, Ontario. Mr. Bingham will be responsible for client services and relationships in Ontario, and for strengthening $\mathrm{CHHI}$ 's ties with its many Ontario partners.

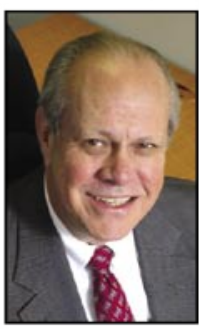

Mr. Bingham first joined CIHI in May of 2002 and became the Director of the Health Report and Analysis branch, where he provided direction in the development of several of $\mathrm{CIHI}$ 's flagship reports. He brinos more than 25 years of varied experience in the public and private sectors of health care to his work at $\mathrm{ClHI}$.

In Ontario. Mr. Bingham spent many vears as a leader in developing health care service restructuring plans, annual operating plans and budgets for several health centres and regional hospitals. Among his many projects, he has led data analysis for the Ontario Joint Policy and Planning Commission and done critical analysis for many Ontario acute and long-term care providers, as well as the Ontario Hospital Association.

The Canadian Institute for Health Information ( $\mathrm{ClHI}$ ) collects and analyzes information on health and health care in Canada and makes it publicly available. Canada's federal, provincial and territorial governments created $\mathrm{ClHI}$ as a notfor-profit independent organization dedicated to forging a common approach to Canadian health information. CIHI's goal: to provide timely, accurate and comparable information. CIHI's data and reports inform health policies, support the effective delivery of health services and raise awareness among Canadians of the factors that contribute to good health.

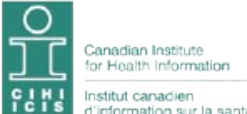

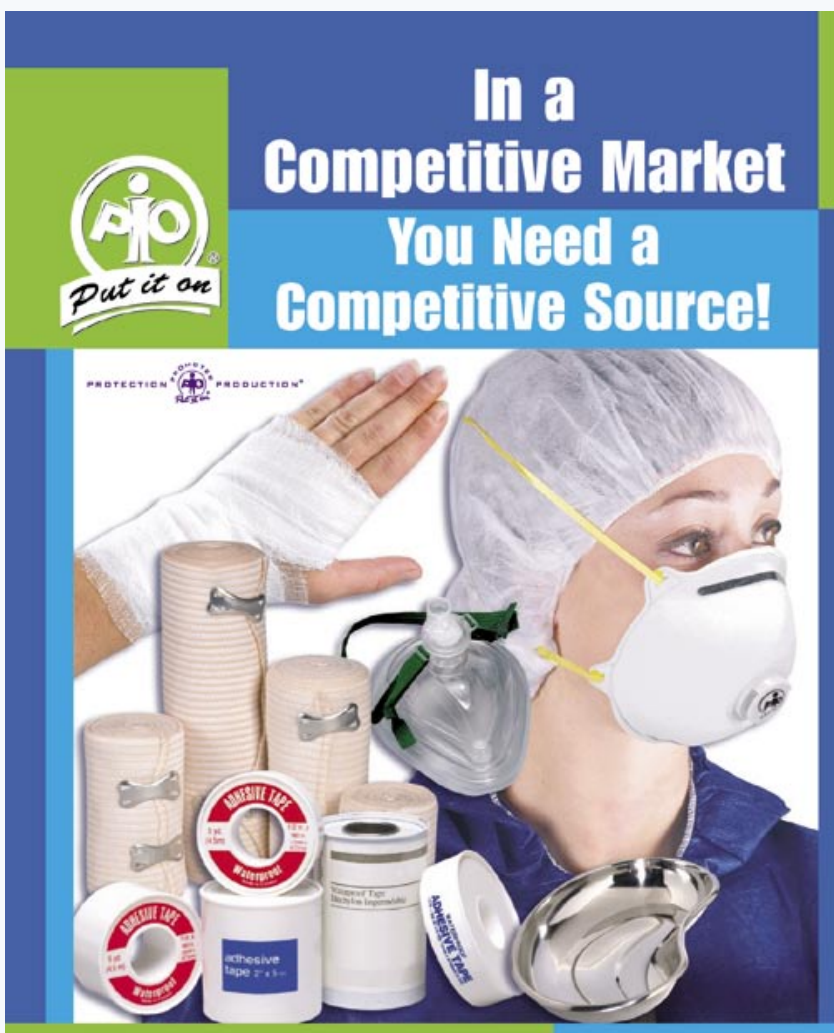

WASIP Ltd. - Toronto, Ontario, Canada Tel: 416.297.5020 / 800.268.3572

Fax: 416.297.0109/800.263.9049 • www.wasip.com

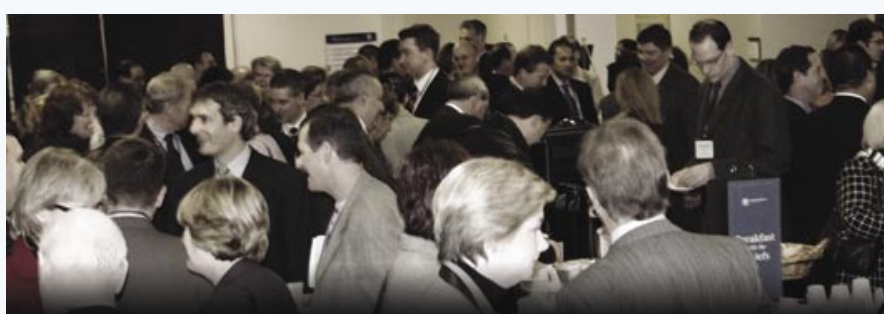

By invitation only. 